\title{
Temperature dependence of gas-phase polycyclic aromatic hydrocarbon and organochlorine pesticide concentrations in Chicago air
}

\author{
Aysun Sofuoglu ${ }^{\mathrm{a}}$, Mustafa Odabasi ${ }^{\mathrm{b}, *}$, Yucel Tasdemir ${ }^{\mathrm{c}}$, Nasrin R. Khalili ${ }^{\mathrm{d}}$, \\ Thomas M. Holsen ${ }^{\text {e }}$ \\ ${ }^{a}$ Department of Chemical Engineering, Faculty of Engineering, Izmir Institute of Technology, Gulbahce-Urla, Izmir, Turkey \\ ${ }^{\mathrm{b}}$ Department of Environmental Engineering, Faculty of Engineering, Dokuz Eylul University, Kaynaklar Campus, 35160 Buca, Izmir, \\ Turkey \\ ${ }^{\mathrm{c}}$ Department of Environmental Engineering, Faculty of Engineering and Architecture, Uludag University, 1609 Gorukle, Bursa, Turkey \\ ${ }^{\mathrm{d}}$ Department of Chemical and Environmental Engineering, Illinois Institute of Technology, 10 West 33rd Street, Chicago, IL 60616, USA \\ ${ }^{\mathrm{e}}$ Department of Civil and Environmental Engineering, Box 5710, Clarkson University, Potsdam, NY 13699, USA
}

Received 26 March 2001; accepted 18 July 2001

\begin{abstract}
The temperature dependence of gas-phase atmospheric concentrations of polycyclic aromatic hydrocarbons (PAHs) and organochlorine pesticides measured in Chicago, IL between June and October 1995 were investigated using plots of the natural logarithm of partial pressures $(\ln P)$ vs. reciprocal mean temperatures $(1 / T)$. For the eight lowest molecular weight PAHs, temperature dependence was statistically significant (at the $95 \%$ confidence level) and temperature accounted for $23-49 \%$ of the variability in gas-phase concentrations. The relatively higher slopes for most of the PAHs suggested that volatilization from local sources and short-range transport influenced their concentrations. For pesticides, temperature dependence was statistically significant for DDD and for trans-nonachlor (at the $95 \%$ and $90 \%$ confidence levels), and was not statistically significant for the other five compounds $(2-18 \%$ of the variability in their gas-phase concentrations). The relatively lower slopes for individual pesticides suggested that they have mostly nonurban and distant sources.

Results of back trajectory analyses suggested that the region, southwest of Chicago, might be an important local or regional source sector for PAHs and organochlorine pesticides. No statistically significant relationship was observed between wind speed and PAH or pesticide concentrations. None of the variables (temperature, wind speed, wind direction, local and regional sources) could fully explain the variation in their concentrations measured in Chicago, therefore, this variation can be attributed to the combined effect of those factors. (C) 2001 Elsevier Science Ltd. All rights reserved.
\end{abstract}

Keywords: Polycyclic aromatic hydrocarbons; Organochlorine pesticides; Air/surface exchange; Temperature dependence

\section{Introduction}

It has been shown that the air concentrations of semivolatile organic compounds (SOCs) have a strong

\footnotetext{
*Corresponding author. Tel.: +90-232-453-1008; fax: +90232-453-0922.

E-mail address: mustafa.odabasi@deu.edu.tr (M. Odabasi).
}

relationship to ambient temperature (Lee and Jones, 1999; Cortes et al., 1998; Hoff et al., 1998; Honrath et al., 1997). As the temperature rises, air concentrations increase as a result of volatilization from surfaces such as soil, atmospheric particles, water, and vegetation. The temperature dependence of gas-phase ambient concentrations of SOCs has been investigated using ClausiusClapeyron plots (Lee and Jones, 1999; Cortes et al., 
1998; Hoff et al., 1998; Honrath et al., 1997; Hillery et al., 1997) and surface exchange models (Wania et al., 1998). The variation in atmospheric SOC concentrations can be quantified using the Clausius-Clapeyron equation

$\ln P=\left(-\Delta H_{\mathrm{v}} / R\right)(1 / T)+$ constant,

where $P$ is the gas-phase SOC partial pressure (atm), $\Delta H_{\mathrm{v}}$ is the enthalpy of vaporization $\left(\mathrm{kJ} \mathrm{mol}^{-1}\right)$, $R$ is the gas constant, and $T$ is the average atmospheric temperature $(\mathrm{K})$ during the sampling period. $\Delta H_{\mathrm{v}}$ is the heat required for phase change of a pure compound. In real environments, Simcik et al. (1999a) suggested that $\Delta H_{\mathrm{v}}$ could be defined as the energy necessary to cause the phase transition from the surface of soil, water or vegetation to the atmosphere. Thus, they referred to this term as $\Delta H_{\mathrm{SA}}$, the enthalpy of surface-air exchange.

It has been suggested that the slopes of ClausiusClapeyron plots can be interpreted as a parameter indicating the relative importance of short- vs. long-range transport (Wania et al., 1998). According to this hypothesis, lower slope values indicate that long-range transport controls ambient SOC concentrations and higher slope values indicate that volatilization from local sources dominate atmospheric concentrations.

Different classes of compounds such as organochlorine pesticides and polycyclic aromatic hydrocarbons (PAHs) will have different environmental behaviors due to their different sources (pesticides - mostly non-urban and distant sources, and PAHs - urban point and nonpoint sources) and physical-chemical properties (vapor pressure, Henry's law constant, air-surface partition coefficient).

The temperature dependency of gas-phase ambient concentrations of different classes of SOCs (polychlorinated biphenyls, polychlorinated naphthalenes and organochlorine pesticides) has been investigated extensively using Clausius-Clapeyron plots (Lee and Jones, 1999; Cortes et al., 1998; Hoff et al., 1998; Honrath et al., 1997; Hillery et al., 1997; Wania et al., 1998; Simcik et al., 1999a; Currado and Harrad, 2000). However, there has been only one study investigating the temperature dependency of gas-phase ambient $\mathrm{PAH}$ concentrations (Gigliotti et al., 2000).

The objective of this study was to compare the temperature dependence of gas-phase atmospheric concentrations of PAHs and organochlorine pesticides measured in Chicago, IL between June and October 1995. Plots of $\ln P$ vs. $1 / T$ were used to test the previously suggested hypotheses (Wania et al., 1998). Back trajectory analyses were also used to provide more information about the principal source sectors associated with high and low concentrations measured at the sampling location.

\section{Experimental}

\subsection{Sampling and analysis}

The sampling and analytical methods are described in detail elsewhere (Cakan, 1999; Odabasi et al., 1999a, b; Odabasi, 1998; Tasdemir, 1997) and will only be briefly described here. Ambient air samples were collected between June and October 1995 on the roof of a fourstory building ( $12 \mathrm{~m}$ height) located on the campus of the Illinois Institute of Technology. All samples were collected during the daytime when there was no rain. Average sampling time was $24 \mathrm{~h}$ over two days $(2 \times 12 \mathrm{~h})$ and the average sampling volume was about $140 \mathrm{~m}^{3}$. Meteorological data was obtained from a tower located on the top of the same building.

Air samples were collected using a modified highvolume sampler, Model PS-1 (General Metal Works Inc.). Particles were collected on glass fiber filters of diameter $11 \mathrm{~cm}$. The gas-phase compounds were collected in a modified cartridge containing XAD-2 resin placed between layers of polyurethane foam (PUF).

All the samples were spiked with surrogate standards prior to extraction in order to determine analytical recovery efficiencies. Samples were Soxhlet-extracted with a mixture of dichloromethane (DCM) : petroleum ether (PE) $(20: 80)$ for $24 \mathrm{~h}$. All sample extracts were concentrated and transferred into hexane using a rotary evaporator and a high-purity stream of nitrogen. After volume reduction to $2 \mathrm{ml}$ and transfer into hexane, samples were cleaned up on an alumina-silicic acid column containing $3 \mathrm{~g}$ silicic acid ( $3 \%$ water) and $2 \mathrm{~g}$ alumina ( $6 \%$ water). The column was prewashed with $20 \mathrm{ml}$ DCM followed by $20 \mathrm{ml}$ PE. The sample in $2 \mathrm{ml}$ hexane was added to the top of column, and PAHs/ pesticides were eluted with $20 \mathrm{ml}$ of DCM. The solvent was exchanged into hexane, and the final sample volume was adjusted to $1 \mathrm{ml}$ by nitrogen blow-down.

Samples were analyzed for PAHs using a HP GC/MS system consisting of a HP Model 5890 Series II gas chromatograph and a HP Model 5971A mass selective detector (MSD). Sample analysis for pesticides was performed with a Hewlett-Packard (HP) 5890 gas chromatograph (GC) equipped with a ${ }^{63} \mathrm{Ni}$ electron capture detector (ECD) (Cakan, 1999; Odabasi et al., 1999a, b).

\subsection{Quality control}

All samples were spiked with surrogate standards, prior to extraction, to determine analytical recovery efficiencies. Recoveries of PAH surrogate standards were $64 \pm 14 \%$ for acenaphthene- $d_{10}, 74 \pm 14 \%$ for phenanthrene- $\mathrm{d}_{10}, \quad 79 \pm 12 \%$ for chrysene- $\mathrm{d}_{12}$, and $67 \pm 13 \%$ for perylene- $d_{12}$. Procedural recoveries of 
organochlorine pesticides were determined externally and they ranged from $51 \pm 7 \%$ to $87 \pm 13 \%$.

Blank PUF cartridges were routinely placed in the field to determine if there was any contamination during sample handling and preparation. The PAH amounts found in the blanks were generally $<10 \%$ of the amount in PUFs. The pesticide amounts found in blanks were generally $<18 \%$ of the amount in PUFs.

Quantifiable amounts were determined from sequential injections of diluted standard solutions of the analyzed compounds. The quantifiable amounts of PAHs ranged from 0.015 to $0.24 \mathrm{ng}$. The average quantifiable amount was $0.5 \mathrm{pg}$ for pesticides.

The limit of detection (LOD, ng) was defined as the mean blank mass + three standard deviations. PAHs benz $[a]$ anthracene through benzo[ $[g, h, i]$ perylene were not detected (nd) in blanks. LODs for PAHs ranged from 20 to $2013 \mathrm{ng}$ for PUFs. In general, PAH amounts in the samples were substantially higher than LODs. LODs for organochlorine pesticides ranged from 1.4 to $8.5 \mathrm{ng}$ for PUFs. Sample quantities exceeding the LOD were quantified and blank-corrected by subtracting the mean blank amount from the sample amount.

The analytical method used for PAHs was tested by analyzing three aliquots of NIST Standard Urban Dust Reference Material (SRM-1649). Concentrations of PAHs found in the SRM-1649, as the percent of NIST certified values, were: benz $[a]$ anthracene, $96 \%$, benzo $[a]$ pyrene, $88 \%$, benzo $[g, h, i]$ perylene, $96 \%$, fluoranthene, $106 \%$, and indeno[1,2-cd]pyrene, $117 \%$.

The MS was tuned daily with perfluorotributylamine. If any key ion abundance observed during daily tuning differed by more than $10 \%$ absolute abundance from that observed during the previous daily tuning, the instrument was retuned. A midrange calibration standard was analyzed for every 12 -h period to confirm GC-MS and GC-ECD performances (i.e. peak area, retention time). Samples were analyzed occasionally as duplicates. Differences in duplicate samples were $<5 \%$.

\section{Results and discussion}

\subsection{Gas-phase ambient concentrations}

Average gas-phase individual PAH concentrations ranged from $0.1 \pm 0.1$ (average $\pm \mathrm{SD}$ ) (benzo $[a]$ pyrene) to $185 \pm 170 \mathrm{ng} \mathrm{m}^{-3}$ (phenanthrene) (Table 1). These concentrations were similar to the ones previously measured in Chicago, IL (Cotham and Bidleman, 1995; Pirrone et al., 1995) and in London (Halsall et al., 1994). Gasphase $\Sigma$ PAH concentrations ranged from 71 to $1331 \mathrm{ng} \mathrm{m}^{-3}$ (average $394 \pm 342 \mathrm{ng} \mathrm{m}^{-3}$ ). By comparison, Simcik et al. (1997) measured a range of $27-430 \mathrm{ng} \mathrm{m}^{-3}$

Table 1

Summary of concentrations and regression parameters for Clausius-Clapeyron plots for individual PAHs and organochlorine pesticides

\begin{tabular}{lcccccc}
\hline PAHs & $\begin{array}{l}\text { Gas-phase concentration } \\
\left(\mathrm{ng} \mathrm{m}^{-3}\right)\end{array}$ & $m$ & $b$ & $n$ & $r^{2}$ & $\begin{array}{l}\text { Significance level } \\
(\%)\end{array}$ \\
\hline Acenaphthene & $64 \pm 77$ & -8760 & 3.4 & 29 & 0.27 & 95 \\
Fluorene & $76 \pm 83$ & -8882 & 4.2 & 29 & 0.35 & 95 \\
Phenanthrene & $185 \pm 170$ & -8476 & 3.8 & 29 & 0.39 & 95 \\
Anthracene & $10 \pm 9$ & -8806 & 1.9 & 30 & 0.34 & 95 \\
Carbazole & $4.3 \pm 4.5$ & -9600 & 3.8 & 29 & 0.39 & 95 \\
Fluoranthene & $35 \pm 27$ & -8538 & 2.3 & 30 & 0.49 & 95 \\
Pyrene & $18 \pm 13$ & -7302 & -2.5 & 30 & 0.41 & 95 \\
Chrysene & $1.1 \pm 0.7$ & -4562 & -14.6 & 30 & 0.23 & 95 \\
Benz[a]anthracene & $0.5 \pm 0.5$ & -3940 & -17.9 & 29 & 0.06 & NS \\
Benzo[b]fluoranthene & $0.2 \pm 0.2$ & -2708 & -22.7 & 31 & 0.05 & NS \\
Benzo[ $k$ ]fluoranthene & $0.2 \pm 0.2$ & -2183 & -24.7 & 29 & 0.04 & NS \\
Benzo[a]pyrene & $0.1 \pm 0.1$ & -1446 & -27.6 & 19 & 0.01 & NS \\
& & & & & & \\
Pesticides & & & & & & \\
$\alpha$-HCH & $0.11 \pm 0.04$ & -1201 & -28.3 & 34 & 0.06 & NS \\
$\gamma$-HCH & $0.15 \pm 0.08$ & -2107 & -25.1 & 37 & 0.07 & NS \\
$\alpha$-Chlordane & $0.12 \pm 0.07$ & -1688 & -27.1 & 33 & 0.04 & NS \\
$\gamma$-Chlordane & $0.13 \pm 0.08$ & -2396 & -24.6 & 35 & 0.08 & NS \\
Trans-nonachlor & $0.08 \pm 0.03$ & -1592 & -27.8 & 34 & 0.09 & 90 \\
DDD & $0.10 \pm 0.05$ & -2803 & -23.2 & 26 & 0.18 & 95 \\
DDT & $0.07 \pm 0.06$ & -1118 & -29.5 & 32 & 0.02 & NS \\
\hline a & & & & &
\end{tabular}

\footnotetext{
${ }^{\text {a }}$ Not statistically significant.
} 
for gas phase $\mathrm{EPAHs}$ at the same site in Chicago in 1994.

Average gas-phase individual organochlorine pesticide concentrations ranged from $0.07 \pm 0.06$ (DDT) to $0.15 \pm 0.08 \mathrm{ng} \mathrm{m}^{-3}(\gamma-\mathrm{HCH})$ (Table 1). These concentrations were within the ranges previously measured in Egbert, Ontario (Hoff et al., 1992) and Chicago, IL (Pirrone et al., 1995). Gas-phase $\Sigma$ pesticide concentrations ranged from 0.24 to $1.35 \mathrm{ng} \mathrm{m}^{-3}$ (average $\left.0.63 \pm 0.22 \mathrm{ng} \mathrm{m}^{-3}\right)$.

\subsection{Effect of temperature on air concentrations of individual PAHs and organochlorine pesticides}

Interpretation of the relationship between atmospheric concentrations of SOCs and temperature is complicated by the presence of confounding factors. In contrast to other compounds for which such analyses have been undertaken, PAHs have a much faster atmospheric degradation rate and seasonally and diurnally variable source strength. These factors could potentially interfere with an analysis of the effect of temperature on atmospheric gas-phase concentrations. In this study, the samples were collected during the daytime in summer and early fall. Therefore, seasonal (i.e. increased fuel use for domestic heating during winter) and diurnal (i.e. increased emissions from motor vehicles due to more traffic during daytime) variations were probably not significant. The temperature dependence of gas-phase atmospheric concentrations of PAHs and organochlorine pesticides were investigated using plots of $\ln P$ vs. $1 / T$ (Eq. (1)). The regression of $\ln P$ against $1 / T$ should be linear with a negative slope $m$ and an intercept $b$ (Currado and Harrad, 2000; Simcik et al., 1999a):

$\ln P=m(1 / T)+b$.

Partial pressures (atm) of individual compounds were calculated for each sample using gas-phase concentrations and the ideal gas law. Natural logarithms of calculated partial pressures were plotted against reciprocal mean temperatures for each sampling period. The mean temperature was obtained by averaging the hourly temperatures over each sampling period and ranged from $11^{\circ} \mathrm{C}$ to $34^{\circ} \mathrm{C}$ during the sampling program. Results for individual PAHs and organochlorine pesticides are presented in Table 1. As shown, for the eight lowest molecular weight PAHs, the temperature dependence of gas-phase concentrations was statistically significant at the $95 \%$ confidence level and the slopes ranged from -1446 to -9600 . Although there are no previously reported values for PAHs to compare with these values, they were within the range of values reported for other SOCs (from 63 to -11556) (Wania et al., 1998; Honrath et al., 1997). For the PAHs, acenaphthene through chrysene, which are found mainly in the gas phase, temperature accounted for $23-49 \%$ of the variability in their concentrations. The relatively higher slopes (from -4562 to -9600 ) of these more volatile PAHs suggested that volatilization from local sources and short-range transport influenced their atmospheric concentrations in Chicago. These results were consistent with the literature suggesting that PAHs have mostly urban, point and non-point sources (Simcik et al., 1999b; Khalili et al., 1995). In a similar study in the New Jersey coastal atmosphere, Gigliotti et al. (2000) reported that temperature accounted for $<25 \%$ of the variability in atmospheric concentrations of relatively more volatile PAHs (compared to $23-49 \%$ for this study).

Although, for the relatively more volatile PAHs, there was a statistically significant temperature dependence, temperature accounted only for $1-6 \%$ of the variability in gas-phase concentrations of less volatile compounds benz $[a]$ anthracene through benzo $[a]$ pyrene. The slopes for these less volatile compounds (from -1446 to -3940) were also lower than the ones obtained for volatile PAHs. It has been suggested that the relatively lower slopes indicate that long-range transport influences ambient concentrations (Hoff et al., 1998; Wania et al., 1998). Strict interpretation of this hypothesis suggests that unlike the volatile PAHs, long-range transport influenced the gas-phase concentration of these less volatile ones. However, this finding contradicts the fact that PAHs have mostly urban, point and nonpoint sources. The lack of temperature dependency of less volatile PAHs may be because their atmospheric concentrations are governed by primary emissions, and temperature-dependent phase transfer processes (with both aerosols and other surfaces) are of minor importance.

For organochlorine pesticides, the temperature dependence of gas-phase concentrations was statistically significant at the $95 \%$ confidence level for DDD, at the $90 \%$ confidence level for trans-nonachlor, and was not statistically significant for the other five compounds. The slopes for the pesticides ranged from -1118 to -2396 , which is within the range previously reported (from -601 to -9281) (Cortes et al., 1998). For organochlorine pesticides, temperature accounted for $2-18 \%$ of the variability in gas-phase concentrations. The relatively lower slopes for individual pesticides suggest that long-range transport influenced their ambient concentrations (Hoff et al., 1998; Wania et al., 1998). It has been suggested that although the use of organochlorine pesticides has been banned or restricted, long-range atmospheric transport and deposition are responsible for much of the current contamination in the Great Lakes region (Cortes et al., 1998). Previously, it was reported that temperature was a significant parameter influencing organochlorine pesticide concentrations for some locations, while it was not significant for 

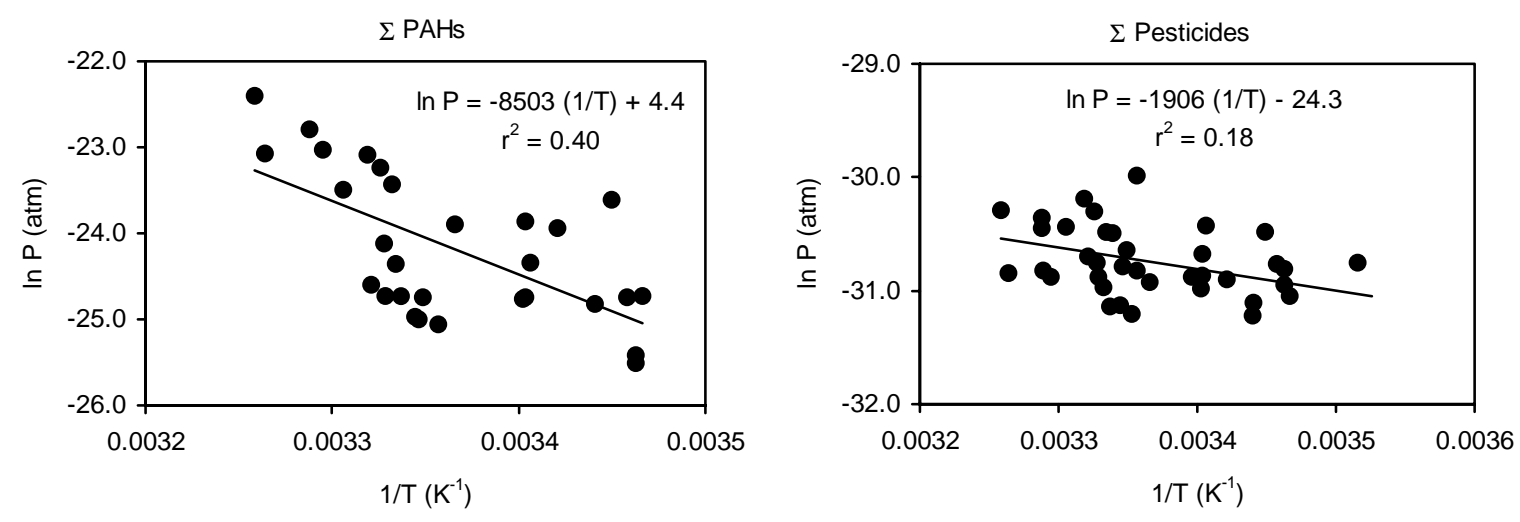

Fig. 1. Clausius-Clapeyron plots for $\Sigma$ PAHs and $\Sigma$ pesticides.

other locations (Cortes et al., 1998; Hoff et al., 1998; Wania et al., 1998). The findings of this study were consistent with the previous studies.

Partial pressures of individual compounds were summed to obtain $\Sigma$ PAH and $\Sigma$ pesticide partial pressures for each sampling period. $\ln P$ values for $\Sigma$ PAHs and $\Sigma$ pesticides were plotted against $(1 / T)$ for each sampling period (Fig. 1). For $\Sigma$ PAHs and $\Sigma$ pesticides, the temperature dependence of gas-phase concentrations was statistically significant (at the 95\% confidence level). The negative slopes found for $\Sigma$ PAHs and $\Sigma$ pesticides indicated that gas-phase concentrations of these groups of SOCs increased with increasing temperature. The slopes for $\Sigma$ pesticides $(-1906)$ and $\Sigma$ PAHs (-8503) were within the range of values reported previously for SOCs (from 63 to -11556) (Hoff et al., 1998; Wania et al., 1998).

The results of the data analysis indicate that gas-phase concentrations of most of the PAHs are temperature dependent and are affected by the local surface-exchange processes even though they are continuously emitted from the urban sources. This observation has been explained by assuming that gas-phase PAHs produced by combustion at elevated temperatures condense to near-source surfaces when they encounter much lower ambient temperatures, after they are emitted. They will then volatilize from these contaminated surfaces as the temperature rises (Gustafson and Dickhut, 1997).

\subsection{Effect of wind speed}

The effect of wind speed $U\left(\mathrm{~m} \mathrm{~s}^{-1}\right)$ on atmospheric concentrations $C_{\mathrm{g}}\left(\mathrm{ng} \mathrm{m}^{-3}\right)$ of individual PAHs and pesticides was investigated using linear regression analysis as

$C_{\mathrm{g}}=m U+b$.

No statistically significant relationship was observed. Previously, it was reported that the wind speed was a significant parameter influencing SOC concentrations for some locations, while it was insignificant for other locations (Currado and Harrad, 2000; Lohmann et al., 2000; Simcik et al., 1999a). It is possible that the effect of the wind speed in this study was masked by the relatively long sampling times (two days during the daytime) and a relatively narrow average wind-speed range encountered $\left(2.2-4.7 \mathrm{~m} \mathrm{~s}^{-1}\right)$.

\subsection{Back trajectory analysis}

The lack of temperature dependency and the variability in measured concentrations that cannot be explained by temperature may be attributed to local or regional emission sources (Gigliotti et al., 2000). To investigate this possibility, back trajectory analyses were performed to determine the source vectors affecting the measured PAH and pesticide concentrations.

Back trajectories were calculated for each sampling day using the HYSPLIT4 model (NOAA Air Resources Laboratory, 1997). Based on the calculated back trajectories, samples were classified as land (SW, NW, or SW-NW), and lake sector samples.

Winds from the east over the lake dilute the urban signal bringing the relatively clean air off the lake, while westerly winds represent the contributions of the diffuse urban and point sources. On the average, gas-phase air concentrations for PAHs and organochlorine pesticides measured in this study were higher when the sampled air masses were from the land sector. The average land to lake sector concentration ratios were 3.2 and 1.2 for $\Sigma$ PAHs and $\Sigma$ pesticides. Average land and lake sample concentrations $\left(568 \pm 376\right.$ and $179 \pm 78 \mathrm{ng} \mathrm{m}^{-3}$, respectively) were statistically different (one-tail $t$-test, 95\% confidence level) for $\Sigma$ PAHs. However, average land and lake sample concentrations $(0.68 \pm 0.26$ and $0.56 \pm 0.13 \mathrm{ng} \mathrm{m}^{-3}$, respectively) were not statistically different for $\Sigma$ pesticides. The results of back trajectory analyses for individual PAHs and pesticides were similar 
to the ones obtained for $\Sigma$ PAHs and $\Sigma$ pesticides. These results suggest that the PAH concentrations measured in this study may be affected by local sources. However, the same conclusion cannot be drawn for the pesticides.

The possible source sectors were further investigated using the samples having the ten highest and ten lowest concentrations for each group of compound (Table 2). The sector most closely associated with highest concentrations was SW and followed by SW-NW for $\Sigma$ PAHs and $\Sigma$ pesticides. The majority of the lowest concentration samples were associated with the lake sector. Results of this evaluation suggest that SW may be an important local or regional source sector and some of the variation in PAH and pesticide concentrations can be attributed to those sources. Steel production with numerous coke ovens and power generation, are the major industries to the south of Chicago. As a result of a source apportionment study, Simcik et al. (1999b) reported that coal combustion accounts for $48 \%$ of the $\Sigma \mathrm{PAH}$ concentration in both Chicago urban and adjacent coastal atmosphere. It was also reported previously that the highest concentrations of PAHs measured at the same site in Chicago, IL were associated with the southwesterly winds (Simcik et al., 1997).

Table 2

Comparison of the source sectors for ten highest and ten lowest concentration samples during the sampling period

\begin{tabular}{llllll}
\hline Sector & \multicolumn{2}{c}{$\Sigma$ PAHs } & & \multicolumn{2}{c}{ Spesticides } \\
\cline { 2 - 3 } \cline { 5 - 6 } & Highest & Lowest & & Highest & Lowest \\
\hline SW & 6 & 2 & 4 & 2 \\
NW & 1 & 0 & 2 & 1 \\
SW-NW & 3 & 2 & 3 & 2 \\
Lake & 0 & 6 & 1 & 5 \\
\hline
\end{tabular}

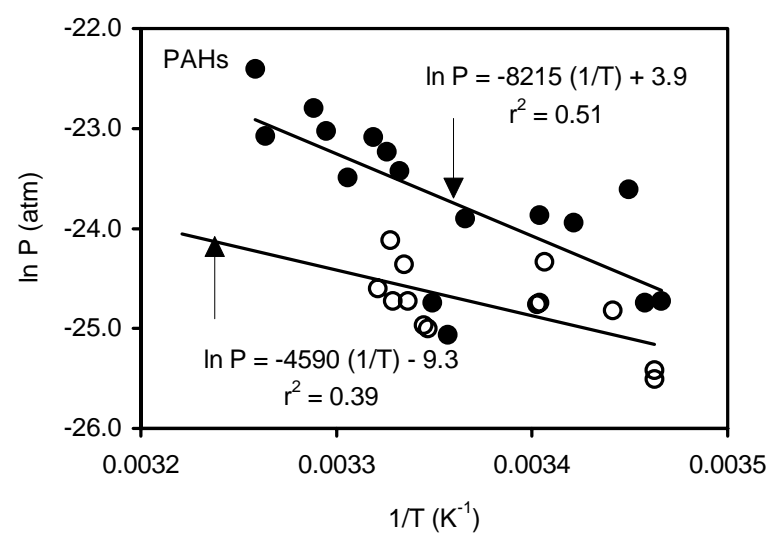

\subsection{Temperature dependence of land and lake sector samples}

Since the slopes of the Clausius-Clapeyron plots can vary widely from site to site due to the competing process of long-range transport of a compound and local volatilization, Hoff et al. (1998) suggested that subsets of data dominated by air-water, air-soil or airvegetation should be used while investigating the temperature dependence of SOCs. The sampled air parcels arriving from different directions reflect the effect of varied sources such as local or regional point and diffuse sources and differential surface exchanges (water, soil and vegetation). Previous studies (Simcik et al., 1999a; Hoff et al., 1998; Honrath et al., 1997) investigated the temperature dependency of SOCs for the cases of flow over land and flow over lake. For transchlordane, Hoff et al. (1998) reported that the slope of $\ln P$ against $(1 / T)$ plot for the flow over land was 1.5 times higher than the one for flow over Lake Ontario. For PCBs, Simcik et al. (1999a) reported that $\Delta H_{\mathrm{SA}}$ values for the Chicago over-lake air masses were about 1.5 times higher than those for over-land flow. This was attributed to local sources affecting the concentrations at the sampling site in Chicago.

The temperature dependence of the $\Sigma$ PAHs and $\Sigma$ pesticides measured in this study for lake and land sector samples are shown in Fig. 2. For $\Sigma$ PAHs, the temperature dependence was statistically significant for lake and land directions (at the $95 \%$ confidence level) and temperature accounted for $39 \%$ and $51 \%$ of the variability in gas-phase concentration for lake- and land-sector samples, respectively. The slope for landsector samples was 1.8 times higher than the one for lake-sector samples. The temperature dependence of individual PAHs acenaphthene through chrysene was statistically significant (at the $95 \%$ confidence level) for land and lake sectors. No statistically significant

Fig. 2. Clausius-Clapeyron plots for $\Sigma$ PAHs and $\Sigma$ pesticides for land (solid symbols) and lake (open symbols) samples.

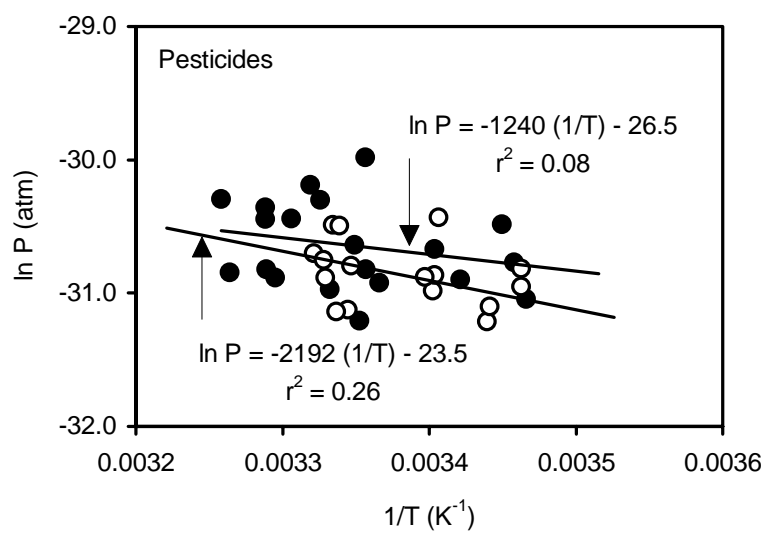


temperature dependence was observed for the compounds benz $[a]$ anthracene through benzo $[a]$ pyrene. The slopes for land-sector samples were approximately two times higher than the ones for lake sector samples. This may be due to short-range transport from the land sector and long-range transport from lake sector or due to differential surface exchange. For $\Sigma$ pesticides, temperature dependency for land-sector samples was not statistically significant, while it was significant (at 95\% confidence level) for lake sector samples. The slope for lake-sector samples was 1.8 times higher than the one for land-sector samples. Temperature accounted for $9 \%$ and $26 \%$ of the variability in gas-phase $\Sigma$ pesticide concentrations for the land- and lake-sector samples, respectively. No statistically significant temperature dependence was observed for individual pesticides for the land sector. The temperature dependence of $\gamma-\mathrm{HCH}, \gamma$-chlordane and trans-nonachlor was statistically significant (at the $90 \%$ or $95 \%$ confidence levels) for the lake-sector samples. The slopes for land-sector samples were approximately two times higher than the ones for lakesector samples.

In summary, none of the variables (temperature, wind speed, wind direction, local and regional sources) could fully explain the variation in PAH and organochlorine pesticide concentrations measured in Chicago, therefore, this variation can be attributed to the combined effect of those factors.

\section{Acknowledgements}

The constructive comments of two anonymous reviewers are greatly acknowledged.

\section{References}

Cakan, A., 1999. The direct measurement of the dry deposition of organochlorine pesticides and polychlorinated naphthalenes. Ph.D. Thesis, Illinois Institute of Technology, Chicago, IL.

Cortes, D.R., Basu, I., Sweet, C.W., Brice, K.A., Hoff, R.M., Hites, R.A., 1998. Temporal trends in gas-phase concentrations of chlorinated pesticides measured at the shores of Great Lakes. Environmental Science and Technology 32, 1920-1927.

Cotham, W.E., Bidleman, T.F., 1995. Polycyclic aromatic hydrocarbons and polychlorinated biphenyls in air at an urban and a rural site near Lake Michigan. Environmental Science and Technology 29, 2782-2789.

Currado, G.M., Harrad, S., 2000. Factors influencing atmospheric concentrations of polychlorinated biphenyls in Birmingham, UK. Environmental Science and Technology 34, 78-82.
Gigliotti, C.L., Dachs, J., Nelson, E.D., Brunciak, P.A., Eisenreich, S.J., 2000. Polycyclic aromatic hydrocarbons in the New Jersey coastal atmosphere. Environmental Science and Technology 34, 3547-3554.

Gustafson, K.E., Dickhut, R.M., 1997. Particle/gas concentrations and distributions of PAHs in the atmosphere of Southern Chesapeake Bay. Environmental Science and Technology 31, 140-147.

Halsall, C.J., Coleman, P.J., Davis, B.J., Burnett, V., Waterhouse, K.S., Harding-Jones, P., Jones, K.C., 1994. Polycyclic aromatic hydrocarbons in UK urban air. Environmental Science and Technology 28, 2380-2386.

Hillery, B.R., Basu, I., Sweet, C.W., Hites, R.A., 1997. Temporal and spatial trends in a long-term study of gasphase PCB concentrations near the Great Lakes. Environmental Science and Technology 31, 1811-1816.

Hoff, R.M., Brice, K.A., Halsall, C.J., 1998. Nonlinearity in the slopes of Clausius-Clapeyron plots for SVOCs. Environmental Science and Technology 32, 1793-1798.

Hoff, R.M., Muir, D.C.G., Grift, N.P., 1992. Annual cycle of polychlorinated biphenyls and organohalogen pesticides in air in Southern Ontario. Environmental Science and Technology 26, 266-275.

Honrath, R.E., Sweet, C.W., Plouff, C.J., 1997. Surface exchange and transport processes governing atmospheric PCB levels over the Lake Superior. Environmental Science and Technology 31, 842-852.

HYSPLIT4 (hybrid single-particle Lagrangian integrated trajectory) model, 1997. Web address: http://www.arl.noaa. gov/ready/hysplit4.html, NOAA Air Resources Laboratory, Silver Spring, MD.

Khalili, N.R., Scheff, P.A., Holsen, T.M., 1995. PAH source fingerprints for coke ovens, diesel and gasoline engines, highway tunnels, and wood combustion emissions. Atmospheric Environment 29, 533-542.

Lee, R.G.M., Jones, K.C., 1999. The influence of meteorology and air masses on daily atmospheric PCB and PAH concentrations at a UK location. Environmental Science and Technology 33, 705-712.

Lohmann, R., Nortcott, G.L., Jones, K.C., 2000. Assessing the contribution of diffuse domestic burning as a source of PCDD/Fs, PCBs and PAHs to the UK atmosphere. Environmental Science and Technology 34, 2892-2899.

Odabasi, M., 1998. The measurement of PAH dry deposition and air-water exchange with the water surface sampler. Ph.D. Thesis, Illinois Institute of Technology, Chicago, IL.

Odabasi, M., Sofuoglu, A., Vardar, N., Tasdemir, Y., Holsen, T.M., 1999a. Measurement of dry deposition and air-water exchange of polycyclic aromatic hydrocarbons with the water surface sampler. Environmental Science and Technology $33,426-434$.

Odabasi, M., Vardar, N., Tasdemir, Y., Sofuoglu, A., Holsen, T.M., 1999b. Polycyclic aromatic hydrocarbons in Chicago air. The Science of the Total Environment 227, 57-67.

Pirrone, N., Keeler, G.J., Holsen, T.M., 1995. Dry deposition of semivolatile organic compounds to Lake Michigan. Environmental Science and Technology 29, 2123-2132.

Simcik, M.F., Zhang, H., Eisenreich, S.J., Franz, T.P., 1997. Urban contamination of the Chicago/Lake Michigan atmosphere by PCBs and PAHs during AEOLOS. Environmental Science and Technology 31, 2141-2147. 
Simcik, M.F., Basu, I., Sweet, C.W., Hites, R.A., 1999a. Temperature dependence and temporal trends of polychlorinated biphenyl congeners in the Great Lakes atmosphere. Environmental Science and Technology 33, 1991-1995.

Simcik, M.F., Eisenreich, S.J., Lioy, P.J., 1999b. Source apportionment and source/sink relationships of PAHs in the coastal atmosphere of Chicago and Lake Michigan. Atmospheric Environment 33, 5071-5079.
Tasdemir, Y., 1997. Modification and evaluation of a water surface sampler to investigate the dry deposition and air/water exchange of polychlorinated biphenyls (PCBs). Ph.D. Thesis, Illinois Institute of Technology, Chicago, IL.

Wania, F., Haugen, J.E., Lei, Y.D., Mackay, D., 1998. Temperature dependence of atmospheric concentrations of semivolatile organic compounds. Environmental Science and Technology 32, 1013-1021. 